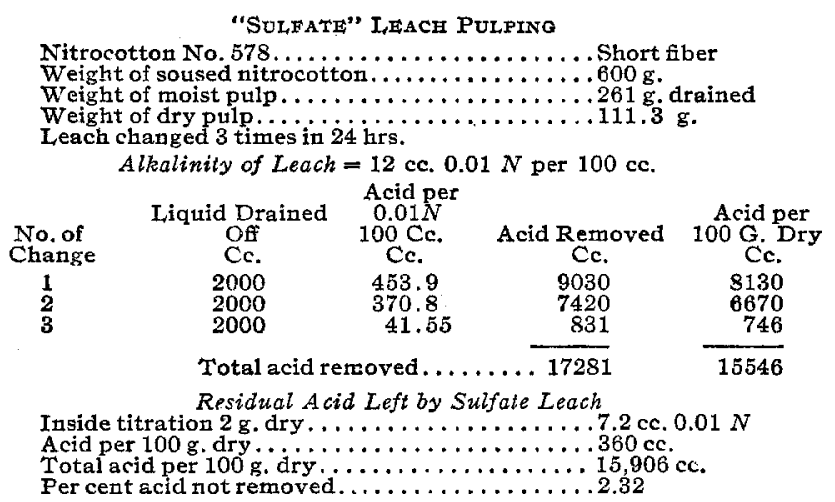

It will be seen that though the total acidity was considerably higher ${ }^{1}$ in the sample used for sulfate pulping the removal of acid, though incomplete with only three leaches, was much better than with "hard" water, only 2.3 per cent of the total acidity being left, as compared with 14 per cent for water. The actual acidities per $1 \mathrm{~g}$. dry were:

$$
\begin{array}{lr}
1 \mathrm{~g} . \text { dry, by water } & 14.7 \mathrm{cc} . \\
1 \mathrm{~g} . \text { dry, by sulfate } & 3.6 \mathrm{cc} .
\end{array}
$$

One important conclusion from these experiments is this. Although, as already stated, the same degree of mechanical subdivision is reached earlier in water than in sulfate, the acid removal lagged behind that by sulfate. It appears evident that merely mechanically shortening and destroying the fibers does not greatly facilitate acid removal, beyond its effect in assisting uniform penetration of large masses. In spite of the fine subdivision of the nitrocotton (see Fig. 9) the latter portions of acid are obstinately retained in water by pulped nitrocotton. In fact, the increased dispersity probably in- creases this retention, in consequence of the greater surface developed. This acid is, however, readily removed by sulfate leach. This tends to confirm our view that the residual acid is held by selective adsorption, not by mechanical occlusion, and that the sulfate leach acts osmotically on the membrane structure of the fiber primarily, and only secondarily on the cell.

It further appears from these results that if pulping or disintegrating were combined with a sulfate leaching process this would be most desirably effected after acid boiling, stabilizing, leaching out of acid, and washing out of sulfate. Actually, this would correspond with the usual practice where pulping is employed, both for guncotton and for celluloid. ${ }^{1}$ Where final boiling in weak alkaline solutions is desired for guncotton, this could be initially effected after pulping in the weakly alkaline water, as this assists the disintegration. In the celluloid industry it is very general to bleach the nitrocellulose after pulping.

We have tested various bleaching methods on sulfate treated cotton, e. g., permanganate followed by bisulfite, "chloride of lime" bleach, sodium hypochlorite, chlorine gas, and hydrogen peroxide, and find them to act at least equally as well on sulfate-leached cotton as on water-washed. Hence, neither the introduction of pulping, nor of pulping and bleaching offers difficulty in the installation of a purification régime utilizing the sulfate leach as the essential deacidifying process.

\section{ACKNOWLEDGME NT}

The writer desires to express his thanks to Mr. W. H. Davis for continued assistance in the experimental work, and to Messrs. A. Armstrong and P. Seel of the Chemical Plant for their coöperation in large-scale trials.

\title{
The Production of Furfural by the Action of Superheated Water on Aqueous Corncob Extract ${ }^{2}$
}

\section{By F. B. LaForge}

Bureat of Chemistry, Washington, D. C.

In a recent paper on the preparation of corncob adhesives by the hydrolysis of field corncobs with hot water under pressure, it was noted that a certain amount of furfural was always produced. ${ }^{3}$ In the present paper a description is given of a method for treatment of corncobs in such a way that the cellulosic material can be obtained and, in addition, an amount of furfural corresponding to 7.76 per cent of the weight of the original cobs.

The method consists in heating the cobs under pressure for a short time with hot water, a procedure which does not injure the cellulosic material. An amount of furfural corresponding to about 2.8 per cent of the weight of the cobs is formed at the same time and is blown off with a certain amount of water when the pressure is released. The crude cellulosic residue is filtered and pressed, and the aqueous liquors, which contain a considerable amount of soluble carbohydrates, are heated with water under pressure, thus causing hydrolysis and formation of a further amount of furfural, sufficient to make a total weight of 7.76 per cent of the original cobs.

A comparison of this process for the production of furfural with those now described in the literature indicates certain

1 It is almost impossible to obtain uniformity in this respect in small samples of "soused" nitrocotton.

- Presented before the Division of Organic Chemistry at the 61st Meeting of the American Chemical Society, Rochester, N. Y., April 26 to 29,1921 .

Chemical Age (N. Y.), 28 (1920), 332; see also Z. angew. Chem., 27 (1914), 654; ThIs JoUrnal, 13 (1921), 133. advantages for the former. Not only is the cellulose saved, but the process has the great advantage of using only water for hydrolysis in place of acid. Moreover it will be noted from the experimental results that the time necessary for handling a given amount of cobs is shorter than is customary by the methods so far described using acid hydrolysis. The method can also be applied to the preparation of furfural from corn husks, corn stalks, and bagasse, and probably from many other plant materials rich in pentosans.

\section{EXPERIMENTAL}

One kilo of cobs was heated in an autoclave of about 6-1. capacity with $4000 \mathrm{cc}$. of water at $180^{\circ}$ to $185^{\circ}$. After this temperature had been maintained for three-quarters of an hour, the pressure was released and the vapors were allowed to pass through a condenser. The amount of condensate thus collected was $815 \mathrm{cc}$. Since $5 \mathrm{cc}$. of this condensate gave (a) 0.3268 g., (b) $0.3255 \mathrm{~g}$. of phloroglucide, 815 cc. contained $28.0 \mathrm{~g}$. of furfural. The cellulosic residue remaining in the autoclave was filtered with pressure, and 2650 cc. of filtrate containing soluble carbohydrate material capable of further hydrolysis to furfural were obtained. The cellulosic residue was washed with $2000 \mathrm{cc}$. of water, pressed again, and set aside for other purposes.

The filtrate obtained from the washings was diluted to 4000 cc. with water and used for heating a second batch of $1 \mathrm{~kg}$. of cobs under the conditions given above. In the same

\footnotetext{
1 Schrimpff, Loc. cit., 96.
} 
way, 825 cc. of distillate were obtained, which contained about $28 \mathrm{~g}$. of furfural. The cellulosic material was filtered by pressure and washed with $2000 \mathrm{cc}$. of water, and again pressed. The filtrate and wash waters from this second kilo of cobs were mixed and concentrated to their original volume of $3175 \mathrm{cc}$. (the $4000 \mathrm{cc}$. minus $825 \mathrm{cc}$. blown off when the pressure was released). This solution, with the $2650 \mathrm{cc}$. obtained from the first kilo of cobs, contained the carbohydrate material from $2 \mathrm{~kg}$. of cobs.

Forty-five hundred cc. of this solution, which represented the soluble extracts from $1540 \mathrm{~g}$. of cobs, were heated in the autoclave at $180^{\circ}$ to $185^{\circ}$. After $15 \mathrm{~min}$. the autoclave was blown off through the condenser as before. The amount of condensate was noted and an equal volume of water was added to the contents of the digester and it was again heated for $15 \mathrm{~min}$. at $180^{\circ}$ to $185^{\circ}$. This was then blown off, the volume of the condensate noted, an equal volume of water added to the digester, and the heating repeated. This was carried out five times, after which so little furfural was being produced that it was not worth while to carry the process further. ${ }^{1}$ The following table denotes the results obtained by five successive heatings of $4500 \mathrm{cc}$. of soluble extractives obtained by the method described above.

\begin{tabular}{|c|c|c|c|c|c|}
\hline $\begin{array}{c}\text { No. } \\
1\end{array}$ & $\begin{array}{c}\text { Condensate } \\
\text { Cc. } \\
750\end{array}$ & $\begin{array}{l}\text { Phloroglu- } \\
\text { cide } \\
\text { G. from } 5 \mathrm{Cc} \text {. } \\
\text { (a) } 0.2770 \\
\text { (b) } 0.2738\end{array}$ & $\begin{array}{c}\text { Furfural } \\
\text { G. in } 5 \text { Cc. } \\
\text { (Av.) } \\
0.1454\end{array}$ & $\begin{array}{c}\text { Furfural in } \\
\text { Condensate } \\
\text { Grams } \\
21.8\end{array}$ & $\begin{array}{c}\text { Furfural } \\
\text { in Con- } \\
\text { densate } \\
\text { Per cent } \\
2.91\end{array}$ \\
\hline 2 & 775 & $\begin{array}{l}\text { (a) } 0.2610 \\
\text { (b) } 0.2625\end{array}$ & 0.1383 & 20.9 & 2.70 \\
\hline 3 & 755 & $\begin{array}{l}\text { (a) } 0.2137 \\
\text { (b) } 0.2180\end{array}$ & 0.1146 & 17.3 & 2.29 \\
\hline 4 & 725 & $\begin{array}{l}\text { (a) } 0.1310 \\
\text { (b) } 0.1240\end{array}$ & 0.0691 & 10.2 & 1.38 \\
\hline 5 & 725 & (a) 0.0752 & 0.0420 & 6.1 & 0.84 \\
\hline
\end{tabular}

If it is desired merely to prepare furfural and not to save the cellulose, the process could be made continuous from the start, following the general procedure just described for the hydrolysis of the soluble carbohydrate extractives. Under these conditions the cellulosic material would be allowed to remain in the digester during the complete process. It should be emphasized, however, that the cellulose may have as great value as the furfural in technical operations and it is of great importance to preserve it from injury by overheating.

\title{
The Color Value of a Tan Liquor as a Function of the Hydrogen-Ion Concentration ${ }^{2,3}$
}

\author{
By John Arthur Wilson and Erwin J. Kern \\ Laboratories of A. F. Gallivi \& SONS Co., MiLWAUKEE, Wisconsin
}

In judging the value of a vegetable tanning extract, tanners of ten place much weight upon the color imparted to skin by solutions of the extract. This has given rise to a movement to try to devise some satisfactory method for measuring the color value of an extract. In Europe the tendency has been toward matching a solution of the extract with standard colored glasses, but apparently the preparation of absolutely standardized glasses is a serious problem. Moreover, the color of a tan liquor is not necessarily a measure of the color it will give to a skin. In this country preference seems to have been given to a method involving the observation of the color of strips of sheep or calf skin tanned in a standard solution of the extract. A strip of tanned skin accompanying the analysis report is apt to find greater favor with the tanner than figures on an arbitrary scale, but this method has sometimes been deceptive, because a given tan liquor may impart different colors to samples of skin from different sources. The present paper does not deal with the question of measuring color values, but with factors powerfully affecting such measurements which in the past have been uncontrolled and apparently often quite unappreciated.

It has long been known that the presence of lime in a tanned skin will cause a darkening of the color. If the skin is treated with mineral acid soon after tanning, the color brightens, but the effect of acid becomes less pronounced the longer the skin is previously allowed to stand exposed to air. In our studies on the effect of change of hydrogen-ion concentration upon tanning, we obtained leather differently colored for each different $\mathrm{pH}$ value of the tan liquor. It was immediately apparent that the color of a tan liquor as well as that of the leather is a function of the hydrogen-ion concentration.

\footnotetext{
1 In large-scale practice the process may be made continuous by keeping the temperature constant and maintaining a constant level in the digester by continuous addition of water or steam.

2 Presented before the Section of Leather Chemistry at the 62ud Meeting of the American Chemical Society, New York, N, Y, September 6 to $10,1921$.

Received August 22, 1921.
}

\section{INDICATOR EFFECT}

Two tan liquors were prepared, one from gambier and the other from quebracho extract. To each was added sufficient phosphoric acid to bring the $\mathrm{pH}$ value to 2.5 , as determined by the hydrogen electrode. The phosphoric acid was added to act as a buffer in preventing large changes in $\mathrm{pH}$ value upon long standing. To equal portions of each, sodium hydroxide was added to give series of tan liquors ranging in $\mathrm{pH}$ value from 3.0 to 12.0 and all having a tannin content of 1 per cent, as determined by the authors' new method. ${ }^{1}$ The gambier series varied in color from light straw at $\mathrm{pH}=$ 3.0 to a very deep red at 12.0. The quebracho series was similar in color excepting that the liquors of lower $p H$ value had a touch of violet. Either series resembled a standard series of colors used in the indicator method of determining hydrogen-ion concentration, except for the fact that a light precipitate formed in all liquors having a $\mathrm{pH}$ value of $4.0 \mathrm{or}$ less. The difference in color was evidently a true indicator effect, for any member of the series could be made to match any other member simply by bringing it to the same $\mathrm{pH}$ value. All members of either series appeared practically identical when brought to a $\mathrm{pH}$ value of 3.0. This complete reversibility of color change, however, was not found when liquors at higher $\mathrm{pH}$ values were allowed to stand long exposed to air.

\section{Oxidation EFfects}

Two complete selies of each extract were poured into test tubes; the tubes of one series of each were tightly stoppered, while the others were left uncovered. Next day the liquors in the stoppered tubes showed practically no change, but the others had become darker in color, the more so the higher the $\mathrm{pH}$ value. When the liquors in a series not exposed to air were all brought to a $\mathrm{pH}$ value of 3.0 , they all assumed practically the same color. But when those of a series that had been exposed to air were all brought to 3.0 , they did not assume the same color, but were darker the higher the $\mathrm{pH}$ 